\title{
Direct and Indirect Suppression of Interleukin-6 Gene Expression in Murine Macrophages by Nuclear Orphan Receptor REV-ERB $\alpha$
}

\author{
Shogo Sato, ${ }^{1}$ Takuya Sakurai, ${ }^{1}$ Junetsu Ogasawara, ${ }^{1}$ Ken Shirato, ${ }^{1}$ Yoshinaga Ishibashi, \\ Shuji Oh-ishi, ${ }^{2}$ Kazuhiko Imaizumi, ${ }^{3}$ Shukoh Haga, ${ }^{4}$ Yoshiaki Hitomi, ${ }^{5}$ Tetsuya Izawa, \\ Yoshinobu Ohira, ${ }^{6}$ Hideki Ohno, ${ }^{1}$ and Takako Kizaki ${ }^{1}$ \\ ${ }^{1}$ Department of Molecular Predictive Medicine and Sport Science, Kyorin University, School of Medicine, \\ 6-20-2 Shinkawa, Mitaka, Tokyo 181-8611, Japan \\ ${ }^{2}$ Department of Respiratory Medicine, National Hospital Organization, Ibarakihigashi National Hospital, 825 Terunuma, \\ Tokai-mura, Naka-gun, Ibaraki 319-1113, Japan \\ ${ }^{3}$ Faculty of Human Sciences, Waseda University, 2-579-15 Mikajima, Tokorozawa, Saitama 359-1192, Japan \\ ${ }^{4}$ Graduate School of Comprehensive Human Sciences, University of Tsukuba, 1-1-1 Tennodai, Tsukuba, Ibaraki 305-8573, Japan \\ ${ }^{5}$ Graduate School of Medical Science, Kanazawa University, Kakumamachi, Kanazawa 920-1192, Japan \\ ${ }^{6}$ Faculty of Health and Sport Science, Doshisha University, Kyotanabe, Kyoto 610-0394, Japan
}

Correspondence should be addressed to Takako Kizaki; kizaki@ks.kyorin-u.ac.jp

Received 16 May 2014; Accepted 5 August 2014; Published 14 October 2014

Academic Editor: Austin J. Cooney

Copyright (C) 2014 Shogo Sato et al. This is an open access article distributed under the Creative Commons Attribution License, which permits unrestricted use, distribution, and reproduction in any medium, provided the original work is properly cited.

It is now evident that many nuclear hormone receptors can modulate target gene expression. REV-ERB $\alpha$, one of the nuclear hormone receptors with the capacity to alter clock function, is critically involved in lipid metabolism, adipogenesis, and the inflammatory response. Recent studies suggest that REV-ERB $\alpha$ plays a key role in the mediation between clockwork and inflammation. The purpose of the current study was to investigate the role of REV-ERB $\alpha$ in the regulation of interleukin-6 (il6) gene expression in murine macrophages. REV-ERB $\alpha$ agonists, or overexpression of rev-erb $\alpha$ in the murine macrophage cell line RAW264 cells, suppressed the induction of $i l 6$ mRNA following a lipopolysaccharide (LPS) endotoxin challenge. Also, rev-erb $\alpha$ overexpression decreased LPS-stimulated nuclear factor $\kappa \mathrm{B}(\mathrm{NF} \kappa \mathrm{B})$ activation in RAW264 cells. We showed that REV-ERB $\alpha$ represses il6 expression not only indirectly through an $\mathrm{NF} \kappa \mathrm{B}$ binding motif but also directly through a REV-ERB $\alpha$ binding motif in the murine il6 promoter region. Furthermore, peritoneal macrophages from mice lacking rev-erb $\alpha$ increased il6 mRNA expression. These data suggest that REV-ERB $\alpha$ regulates the inflammatory response of macrophages through the suppression of il6 expression. REV-ERB $\alpha$ may therefore be identified as a potent anti-inflammatory receptor and be a therapeutic target receptor of inflammatory diseases.

\section{Introduction}

The human genome contains 48 nuclear hormone receptor genes, comprising a large family of ligand-dependent transcription factors. In contrast with most classic receptors, nuclear hormone receptors modulate transcription by binding directly to DNA, and ligand interactions occur primarily within the cell cytosol or nucleus. Nuclear hormone receptors are now recognized as key intermediaries between the molecular clock machinery and a wide array of physiological processes [1]. In particular, REV-ERB $\alpha$, one of the nuclear hormone receptors encoded by $n r l d l$, is a crucial regulator of lipid, lipoprotein metabolism, and inflammation [1].

REV-ERB $\alpha$, one of the key clock genes, is a part of the clock machinery and plays an important role in maintaining the proper rhythm of circadian timing [2]. REV-ERB $\alpha$ binds as a monomer to the retinoic acid receptor-related orphan receptor (ROR) response elements (ROREs) composed of a 
$6 \mathrm{bp}$ A/T-rich sequence immediately preceding a site with the core motif of (A/G)GGTCA [3]. It also binds as a homodimer to the RevDR2 response element, which is composed of a $6 \mathrm{bp}$ A/T-rich sequence immediately preceding a site with a tandem repeat of two (A/G)GGTCA motifs spaced by two nucleotides [4].

Our recent work has demonstrated that REV-ERB $\alpha$ suppresses chemokine ( $C-C$ motif) ligand 2 ( $c c l 2)$ gene expression directly through a RORE in the $c c l 2$ promoter region [5]. These results implicate $\mathrm{REV}-\mathrm{ERB} \alpha$ as a critical intermediary between the core clockwork and inflammatory pathways. Gibbs et al. [6] have demonstrated that the administration of a REV-ERB $\alpha$ ligand or a genetic knockdown of rev-erb $\alpha$ expression is effective at modulating the production and release of the proinflammatory cytokine interleukin-6 (IL6). Furthermore, Journiac and coworkers [7] have shown that 2 and 3 putative ROREs have also been found in the il6 promoter region of mice and rats, respectively [7]. However, it is unclear whether the putative ROREs in the murine il6 promoter are sensitive to $\mathrm{REV}-\mathrm{ERB} \alpha$ regulation. In some cases, there are several similarities and differences in the inflammatory response to endotoxin in mice and humans [8]. Therefore, it is important to demonstrate the impact of REV$\mathrm{ERB} \alpha$ on il6 gene in murine immune cells as well as humans.

Results from the current study showed that REV-ERB $\alpha$ directly and indirectly suppresses il6 gene expression in macrophages through a RORE and a nuclear factor $\kappa \mathrm{B}$ response element (NF $\kappa \mathrm{BRE})$, respectively, in the murine il6 promoter region. Furthermore, we observed increases in il6 gene expression in peritoneal macrophages from mice lacking $r e v$-erb $\alpha$. REV-ERB $\alpha$ may therefore be a key link between the clockwork and inflammation.

\section{Materials and Methods}

2.1. Animals. C57BL/6J mice and B6.CgNrld1<tm1Ven $>/$ LazJ mice were obtained from Sankyo Labo Service (Tokyo, Japan) and Jackson Laboratories (Bar Harbor, ME), respectively. The mice were housed in plastic cages and reared at $23^{\circ} \mathrm{C}$ with a $12 \mathrm{~h}$ light/dark cycle. Food and water were available ad libitum. All animals were cared for in accordance with the Guiding Principles for the Care and Use of Animals approved by the Council of the Physiological Society of Japan, based upon the Declarations of Helsinki, 1964.

2.2. Preparation and Culture of Peritoneal Macrophages. Peritoneal macrophages were collected from 2-month-old C57BL/6J mice and rev-erbo ${ }^{-/-}$mice and cultured as described previously [5, 9-11]. The cells from C57BL/6J mice were treated with or without REV-ERB $\alpha$ agonist, 2 or $20 \mu \mathrm{M}$ GSK4112 (Sigma Aldrich), for $16 \mathrm{~h}$ in the absence or presence of $1 \mu \mathrm{g} / \mathrm{mL}$ lipopolysaccharide (LPS) from Escherichia coli 055 (Sigma Aldrich, St. Louis, MO). GSK4112 was dissolved with DMSO, and the control cells were treated using the same volume of DMSO. The cells from rev-erb $\alpha^{-/-}$mice were stimulated with or without LPS for $24 \mathrm{~h}$.
2.3. Cell Line Culture. The murine macrophage cell line RAW264 (RCB0535) was purchased from RIKEN Cell Bank (Ibaraki, Japan) and cultured as described previously [5, 9, $10,12]$. To study the effects of REV-ERB $\alpha$ agonists on il6 gene expression, the cells were treated with or without $20 \mu \mathrm{M}$ GSK4112 or $1 \mu \mathrm{g} / \mathrm{mL}$ LPS for $16 \mathrm{~h}$.

2.4. Real-Time Quantitative PCR ( $q P C R)$. Total cellular RNA was prepared from peritoneal macrophages using an RNeasy Mini Kit (Qiagen, Hilden, Germany) and from RAW264 cells using RNAiso reagent (Takara bio, Siga, Japan). Extracted RNA was reverse-transcribed using a High-Capacity cDNA Reverse Transcription Kit (Applied Biosystems, Foster City, CA) with random primers. The reaction mixture was amplified in a Power SYBR Green Master Mix (Applied Biosystems) using a 7500 Real-Time PCR System (Applied Biosystems) with $200 \mathrm{nM}$ oligonucleotide primers (forward and reverse). The oligonucleotide sequences used for qPCR were as follows: il6: 5'-GAT GGA TGC TAC CAA ACT GGA-3' (forward), $5^{\prime}$-CCA GGT AGC TAT GGT ACT CCA GAA-3' (reverse); $\beta a c t i n$ ( $a c t b$, internal control), $5^{\prime}$-AAG GCC AAC CGT GAA AAG AT-3' (forward), and $5^{\prime}$-GTG GTA CGA CCA GAG GCA TAC-3' (reverse). The expression of the target gene was normalized to the housekeeping gene $a c t b$.

2.5. rev-erbo or ror $\alpha$ Plasmid Constructs and Stable Transfection. A stable rev-erb $\alpha$ transfectant (RAWrev) and the control cell line (RAWvecB) and a stable ror $\alpha$ transfectant (RAWror) and the control cell line (RAWvecA) were established as described previously [5].

2.6. Western Blot Analysis. Nucleic and cytosolic protein was extracted as described previously $[5,10,13]$. Extracted proteins were separated by SDS-PAGE and then transferred to a polyvinylidene difluoride membrane (Millipore, Milford, MA). Membranes were blocked with 5\% nonfat dried milk in TBST and then immunoblotted with rabbit polyclonal Abs against NF $\kappa$ B p65 (sc-372, Santa Cruz Biothechnology, Santa Cruz, CA), $\alpha$-Tublin ( $\alpha$-Tub, ab7291, Abcam, Cambridge, UK), or TATA binding protein (TBP, ab51841, Abcam). Thereafter, HRP-conjugated donkey anti-rabbit or anti-mouse IgG secondary Abs (GE Healthcare Japan, Tokyo, Japan) was applied. The immunoreactivity was visualized with an ECL reagent (Bio-Rad, Hercules, CA).

2.7. EMSA. Nuclear extracts were prepared as described $[5,10,13]$. The murine $\mathrm{NF} \kappa \mathrm{B}$ consensus oligonucleotide probe $\left(5^{\prime}\right.$-AGT TGA GGG GAC TTT CCC AGG C-3 ${ }^{\prime}$ ) was labeled with biotin. The nuclear protein $(2.5 \mu \mathrm{g})$ and labeled oligonucleotide probe $(20 \mathrm{fmol})$ were incubated in $10 \mathrm{mM}$ HEPES-KOH, pH 7.8, $50 \mathrm{mM} \mathrm{KCl,} 0.2 \mathrm{mM}$ EDTA, $10 \%$ glycerol, $1 \mu \mathrm{g}$ poly (dI-dc), $0.05 \%$ NP- 40 , and $5 \mathrm{mM}$ DTT at room temperature for $20 \mathrm{~min}$, electrophoresed in $4.5 \%$ polyacrylamide gels, transferred onto a nylon membrane (Biodyne, Pall Corporation, Pensacola, FL), and UV crosslinked. To detect the signals, a Chemiluminescent Nucleic Acid Detection Module (Thermo Fisher Scientific, Rockford, IL) was used according to the manufacturer's protocol. 
2.8. Luciferase Reporter Assay. For the analysis of the promoter activity of the $\mathrm{NF} \kappa \mathrm{B}$-responsive promoter reporter luciferase construct, the cells were transfected with $\mathrm{pNF} \kappa \mathrm{B}-$ Luc (Clontech, Palo Alto, CA) using a LipofectAMINE Reagent (Invitrogen, Carlsbad, CA), and luciferase activity was determined using a Luciferase Assay System Kit (Promega, Madison, WI).

For the analysis of il6 promoter activity, the murine il promoter (distal fragment, -1029 to +31 ; proximal fragment, -649 to +31$)$ was amplified from mouse genomic DNA (Promega) using an LA Taq polymerase (Takara bio) and was subcloned into $\mathrm{PCR}-\mathrm{XL}-\mathrm{TOPO}$ vector (Invitrogen). The subcloned fragments were digested at KpnI/XhoI sites and cloned into pGL3 vector (Promega) at the corresponding sites. The cells were transiently transfected by using a LipofectAMINE Reagent with distal or proximal constructs containing the luciferase reporter gene, and luciferase activity was determined with a Dual Luciferase Assay System Kit (Promega). Activity was normalized relative to an internal cotransfected constitutive control (Renilla luciferase expression vector, $\mathrm{pRL}-\mathrm{TK}$ vector, Promega), as described $[5,10,12]$.

2.9. Mutagenesis. The il6 promoter mutant construct was made by using a QuickChange Lightning Site-Directed Mutagenesis Kit (Stratagene, La Jolla, CA) as described [5, 12]. The proximal RORE ( -529 to -518$)$ was mutated from AAA CTC AGG TCA to AAA CTC AGG $\underline{C} \underline{T}$ by using the mutant primers $5^{\prime}$-CTG AAA AAA CTC AGG $\underline{\text { CCT }}$ GAA CAT CTG TAG- $3^{\prime}$ (forward) and $5^{\prime}$-CTA CAG ATG TTC AGG CCT GAG TTT TTT CAG-3' (reverse) for the distal and proximal il6 promoter constructs mutagenesis (underline, mutant sequences). The NFkBRE (-91 to -82) was mutated from GGG ATT TTC C to GGG CCC TTC $\mathrm{C}$ by using the mutant primers $5^{\prime}$-GAT TTT TAT CAA ATG TGG GCC CTT CCC ATG AGT CTC-3' (forward) and $5^{\prime}$-GAG ACT CAT GGG AAG GGC CCA CAT TTG ATA AAA ATC-3' (reverse) for the proximal il6 promoter constructs mutagenesis.

2.10. Statistical Analysis. The results were expressed as the means \pm S.E. When two means were compared, a Student's $t$ test for unpaired samples was conducted. For more than two groups, the statistical significance of the data was assessed by ANOVA. When significant differences were found, individual comparisons were made between groups by using the $t$ statistic and adjusting the critical value according to the Tukey-Kramer method. Differences were considered significant at $P<0.05$.

\section{Results}

3.1. REV-ERB $\alpha$ Agonists Suppress il6 Induction following LPS Stimulation. To determine the role of REV-ERB $\alpha$ in inflammatory responses, we analyzed the effects of the REV$\mathrm{ERB} \alpha$ agonist, GSK4112, on the gene expression of il6 as a crucial inflammatory molecular element in macrophages. The induction of il6 mRNA after LPS stimulation was dose-dependently repressed by the addition of GSK4112 in peritoneal macrophages (Figure 1(a)). Furthermore, as shown in Figure 1(b), qPCR analysis confirmed that GSK4112 treatment also decreased the induction of il6 mRNA after LPS stimulation in murine macrophage cell line RAW264 cells as well as peritoneal macrophages. These data suggest that activation of REV-ERB $\alpha$ led to the suppression of il6 gene induction in macrophages.

3.2. rev-erbo Overexpression Represses il6 Expression. To investigate the potential role of REV-ERB $\alpha$ in il6 expression in macrophages, a stable rev-erb $\alpha$ transfectant (RAWrev) and the control cell line (RAWvecB) were established using RAW264 cells [5]. As seen in Figure 1(c), overexpression of rev-erb $\alpha$ repressed the gene expression of il6 in both the absence and presence of LPS, suggesting that REV-ERB $\alpha$ was involved in the suppression of il6 gene expression in macrophages.

3.3. ror $\alpha$ Overexpression Enhances il6 Expression. REV-ERB $\alpha$ is known to cross-talk with ROR $\alpha$ (orphan nuclear receptor encoded by nrlfi), another of the clock genes that has similar DNA binding specificity to REV-ERB $\alpha$ and competes for the binding of REV-ERB $\alpha$ [14-16]. Whereas REV$\mathrm{ERB} \alpha$ represses transcription from these sites of the target genes, $\operatorname{ROR} \alpha$ acts as a transcriptional activator $[3,4,17]$. From these findings, we hypothesized that ROR $\alpha$ might positively regulate il6 expression and established a stable ror $\alpha$ transfectant (RAWror) and the control cell line (RAWvecA) using RAW264 cells [5]. Interestingly, overexpression of ror $\alpha$ enhanced the gene expression of il6 in the absence of LPS, whereas it repressed the gene expression of $i l 6$ in the presence of LPS (Figure 1(d)), indicating that regulation of il6 gene expression by ROR $\alpha$ is different between nonactivated and activated states in macrophages.

3.4. REV-ERB $\alpha$ Suppressed NFKB Activity. The il6 gene contains a functional $\kappa \mathrm{B}$ element in its promoter region [18]. Thus, activation of $\mathrm{NF} \kappa \mathrm{B}$ leads to the transcription of this proinflammatory gene. Therefore, we next investigated whether REV-ERB $\alpha$ regulates $\mathrm{NF} \kappa \mathrm{B}$ activity in macrophages. As shown in Figure 2(a), cytosolic expression and LPSinduced nuclear translocation of $\mathrm{NF} \kappa \mathrm{B}$ subunit p65 were attenuated in RAWrev cells, compared with RAWvecB cells. No marked change in inhibitory $\kappa \mathrm{B}$ (I $\kappa \mathrm{B})$ expression was observed between RAWrev and RAWvecB cells (data not shown). Furthermore, LPS-induced NFאB activation in RAWrev cells was markedly lower than that in RAWvecB cells (Figure 2(b)). In addition, REV-ERB $\alpha$ attenuated the promoter activity of the $\mathrm{NF} \kappa \mathrm{B}$-responsive promoter reporter luciferase construct in both the absence and presence of LPS in macrophages (Figure 2(c)). These results strongly suggest that REV-ERB $\alpha$ suppresses LPS-enhanced NF $\kappa$ B activity in macrophages.

3.5. REV-ERB $\alpha$ Represses the Activity of the Murine il6 Promoter. Two putative ROREs have been found in the mouse il6 promoter sequence [7]. Therefore, to determine whether the putative ROREs in the il6 promoter are sensitive 


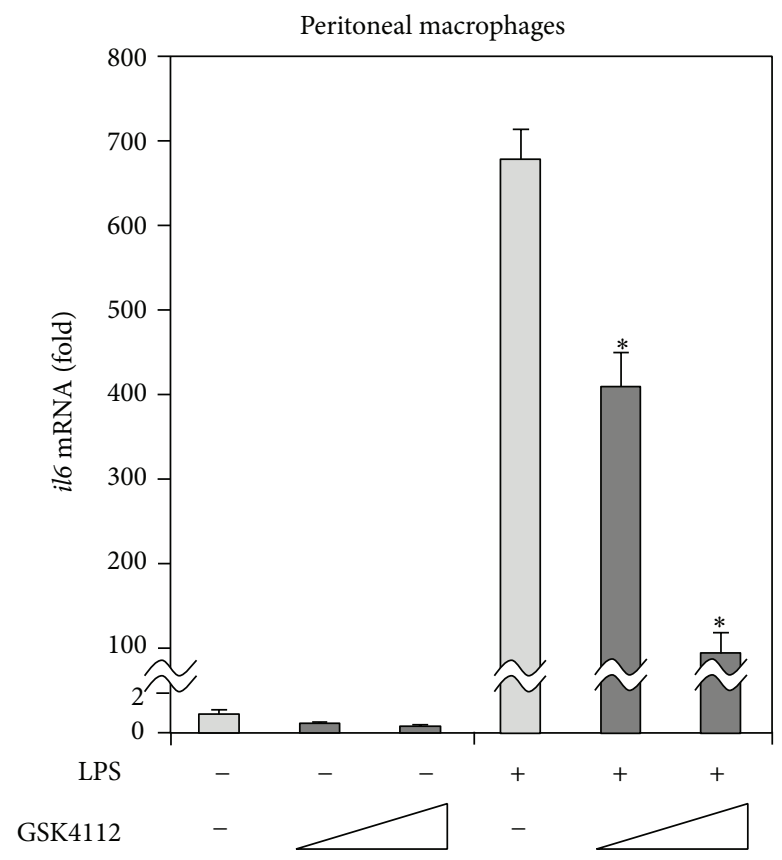

(a)

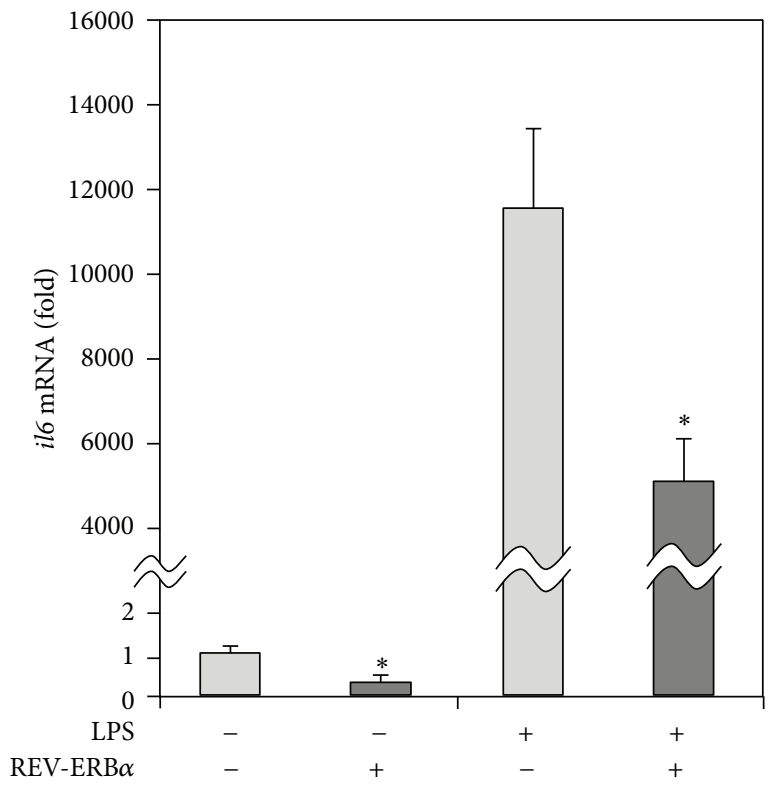

(c)

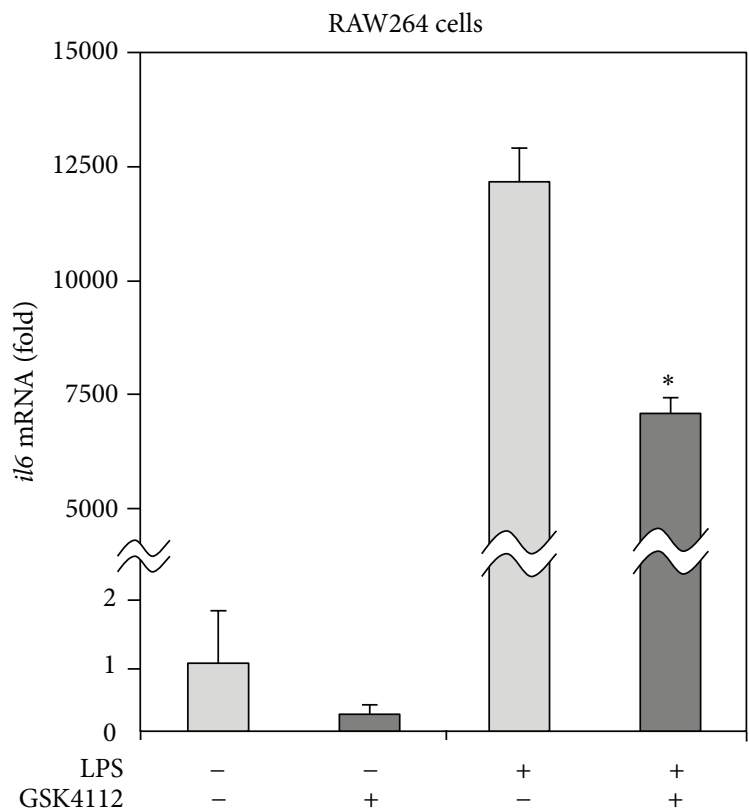

(b)

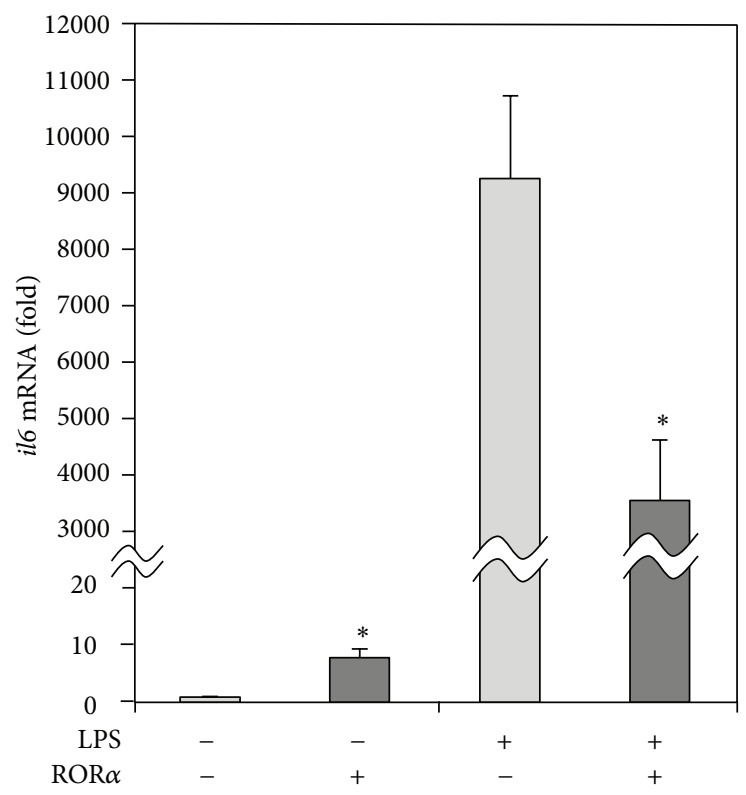

(d)

FIGURE 1: REV-ERB $\alpha$ represses il6 gene induction following a LPS challenge in macrophages. (a) Peritoneal macrophages were harvested as adherent cells from 2-month-old C57BL/6J mice and were either untreated or treated with $1 \mu \mathrm{g} / \mathrm{mL}$ LPS or 2 or $20 \mu \mathrm{M}$ GSK4112 for $16 \mathrm{~h}$. (b) Murine macrophage cell line RAW264 cells were either untreated or treated with $1 \mu \mathrm{g} / \mathrm{mL}$ LPS or $20 \mu \mathrm{M}$ GSK4112 for $16 \mathrm{~h}$. (c) RAW264 cells transfected with or without rev-erb $\alpha$ were either untreated or treated with $1 \mu \mathrm{g} / \mathrm{mL}$ LPS for $24 \mathrm{~h}$. (d) RAW264 cells transfected with or without ror $\alpha$ were either untreated or treated with $1 \mu \mathrm{g} / \mathrm{mL}$ LPS for $24 \mathrm{~h}$. The gene expression of $i l 6$ was analyzed by qPCR. For normalization, actb mRNA was used. The data are presented as the means \pm S.E. $(n=3-4) .{ }^{*} P<0.05$ versus cells treated with LPS and without GSK4112 or versus vector control.

to $\mathrm{REV}-\mathrm{ERB} \alpha$ regulation, we cloned il6 promoters with different lengths - a distal promoter that included one RORE located in the distal region and one RORE located in the proximal region, and a proximal promoter that included one RORE located in the proximal region-into a luciferase reporter vector. Then, these two constructs were transiently transfected into cell lines, RAWrev and RAWvecB cell lines. The activities of each longitudinal promoter in RAWrev cells were considerably lower than those in RAWvecB cells in both the absence and presence of LPS (Figure 3(a)). We 

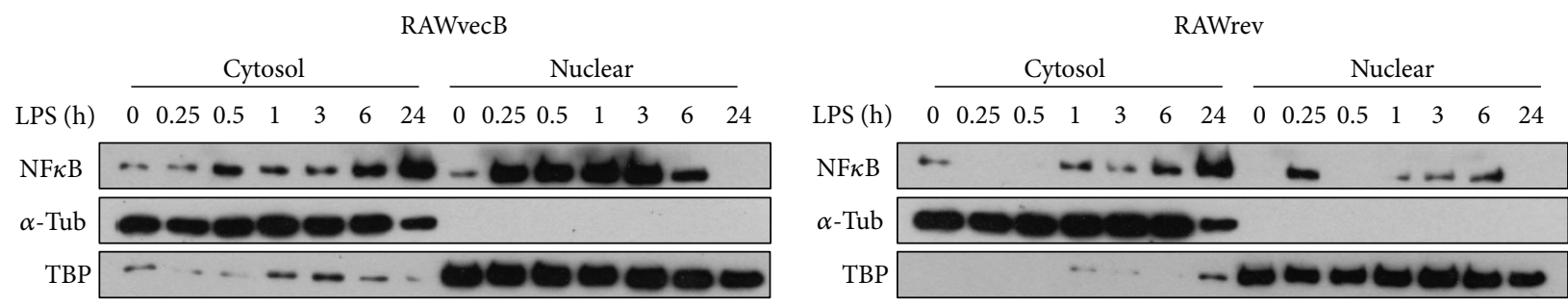

(a)

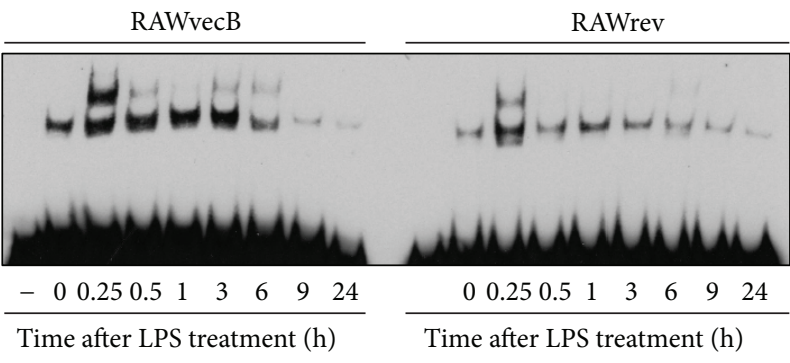

(b)

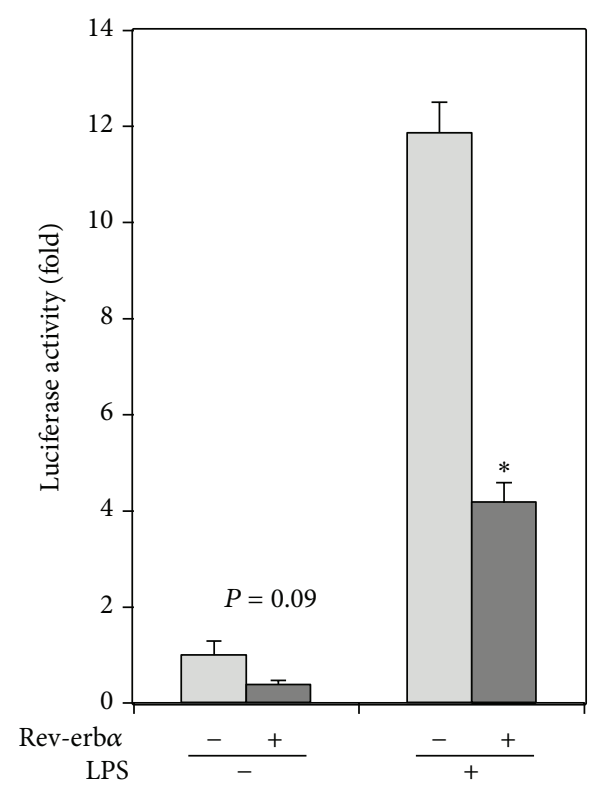

(c)

FigurE 2: REV-ERB $\alpha$ represses NF $\kappa$ B activation in macrophages. (a) Nuclear and cytoplasmic fractions of each cell untreated or treated with LPS for various durations were analyzed by Western blot for $\mathrm{p} 65 \mathrm{NF} \kappa \mathrm{B}, \alpha$-Tub, and TBP. Detection of $\alpha$-Tub and TBP is used as marker of nuclear and cytoplasmic fractions, respectively. (b) Each cell was stimulated with LPS for varying durations and NF $\kappa$ B activation was analyzed by EMSA. Data shown are representative of three separate experiments. (c) Each cell was transiently transfected with NF $\mathrm{B}$-responsive promoter reporter luciferase construct and luciferase activities in each cell stimulated either with or without LPS for $24 \mathrm{~h}$ were analyzed. The data are presented as the means \pm S.E. from sextuplicate cultures. ${ }^{*} P<0.01$ versus vector control.

next investigated whether two ROREs in the il6 promoter are necessary for REV-ERB $\alpha$-mediated repression. As shown in Figure 3(b), the mutation of the proximal RORE abolished the repression of the promoter activities in RAWrev transfected with the distal construct as well as the proximal construct in the absence of LPS. These results suggest a critical role for the proximal RORE in REV-ERB $\alpha$-mediated repression of il6 expression. However, the mutation of the proximal RORE still repressed the promoter activities in RAWrev transfected with the distal construct as well as the proximal construct in the presence of LPS (Figure 3(b)), indicating that $\mathrm{REV}-\mathrm{ERB} \alpha$ repressed il 6 promoter activity through other transcriptional regulators such as $\mathrm{NF} \kappa \mathrm{B}$, which was independent of the direct binding of REV-ERB $\alpha$ to the RORE in the promoter.

3.6. REV-ERB $\alpha$ Represses il6 Promoter Activity, Independent of $N F \kappa B$. To dissect the effect of $\mathrm{NF} \kappa \mathrm{B}$ on il6 promoter activity, we used point-mutated variants in the response element of $\mathrm{NF} \kappa \mathrm{B}$. The activity of an il6 promoter containing an NF $\kappa$ BRE mutated construct in RAWrev cells was lower than that in RAWvecB cells in both the absence and presence of LPS (Figure 3(c)). These results show that REV-ERB $\alpha$ repressed il6 promoter activity, independent of $\mathrm{NF} \kappa \mathrm{B}$. A double mutation of RORE and NF $\kappa$ BRE completely abrogated the suppression of the promoter activity in RAWrev cells in both the absence and presence of LPS (Figure 3(c)). These results suggest both a direct and an indirect repression of the il6 promoter activity by REV-ERB $\alpha$.

3.7. ROR $\alpha$ Enhances the Activity of Murine il6 Promoter. Because ROR $\alpha$ activates target genes via ROREs in their promoters, we reasoned that ROR $\alpha$ might positively regulate il6 promoter activity. Therefore, we transiently transfected the distal and the proximal il6 promoter constructs into RAWror and RAWvecA cells. The activity of each of the liner promoter in the RAWror cells was considerably higher than that in RAWvecA cells in the absence of LPS, whereas 


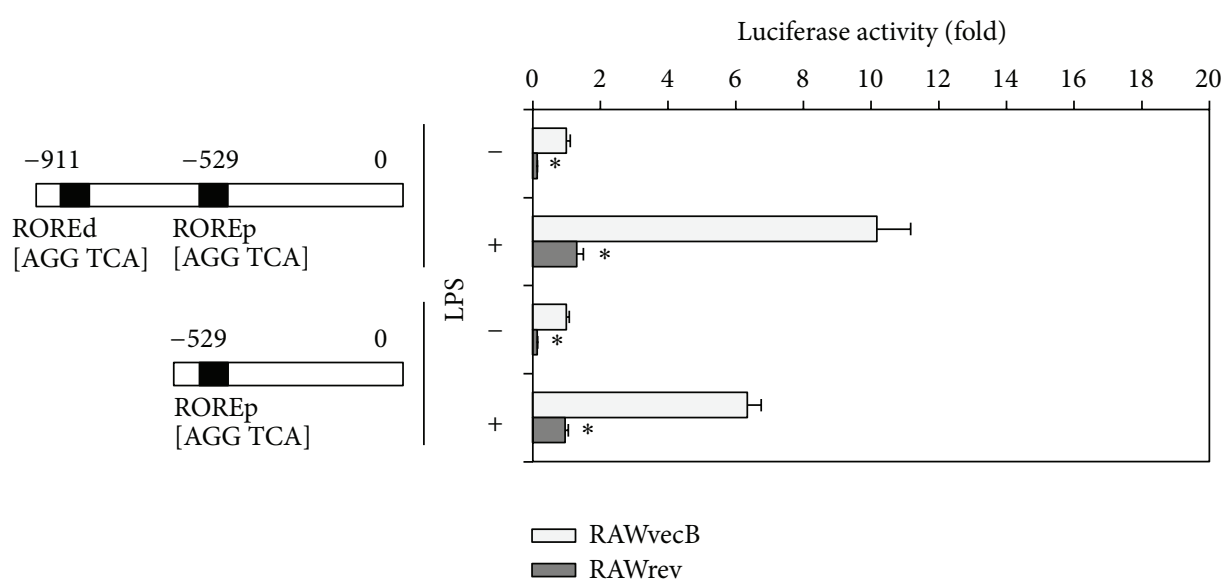

(a)

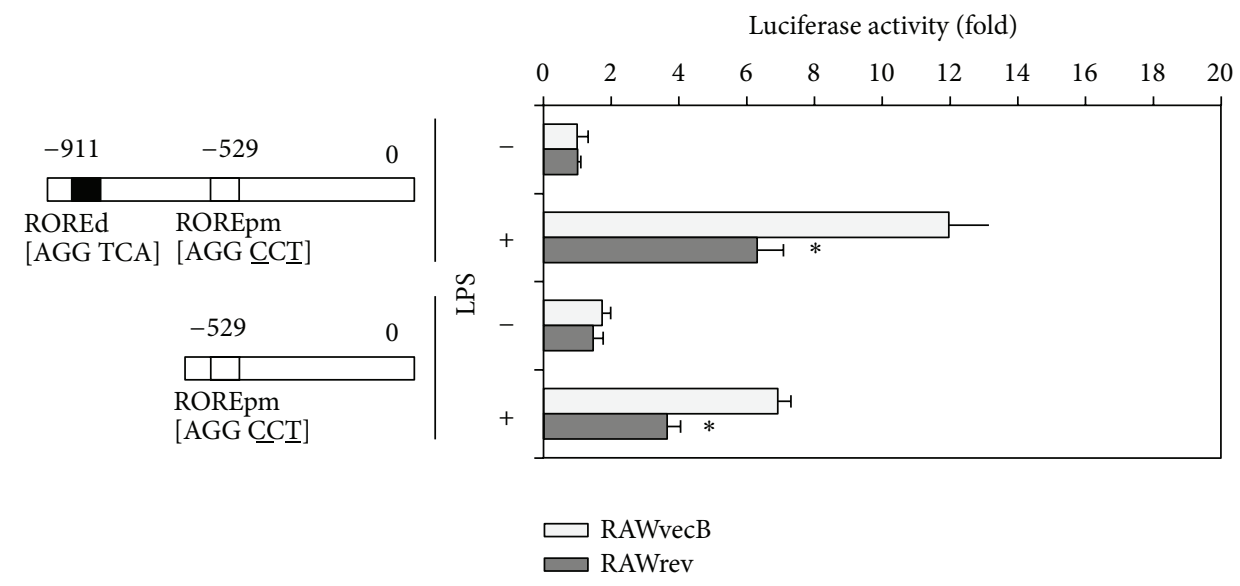

(b)

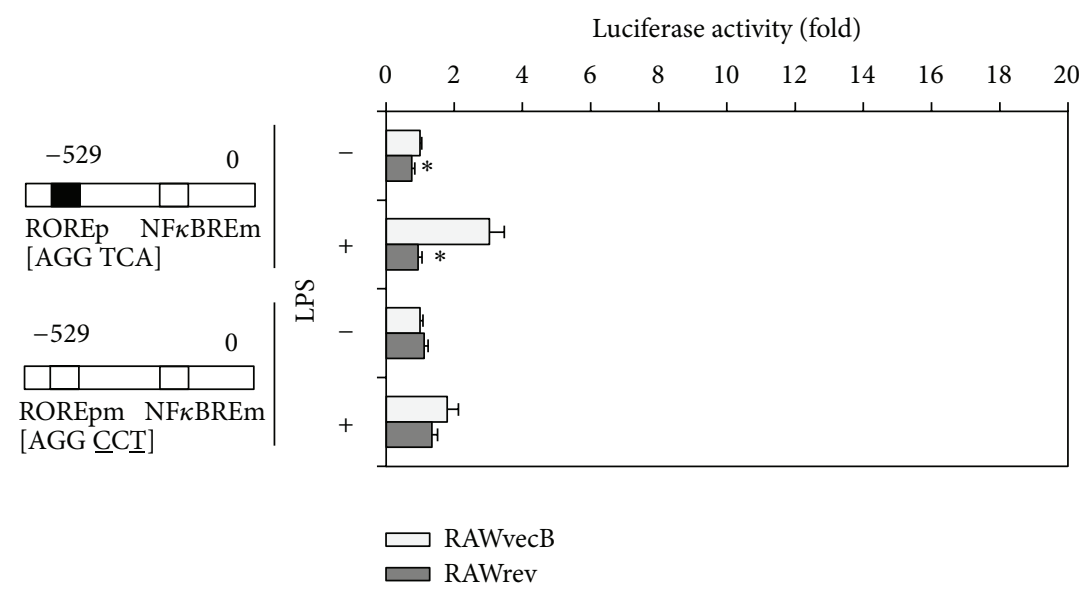

(c)

Figure 3: REV-ERB $\alpha$ represses il6 promoter activity, independent of the inhibition of NF $\kappa$ B signaling. (a) RAWrev and RAWvecB cells were transiently transfected with luciferase reporter construct containing either a distal or a proximal construct of $i l 6$ promoter. After treatment with or without $1 \mu \mathrm{g} / \mathrm{mL}$ LPS for $24 \mathrm{~h}$, luciferase activities were determined. ROREd, distal RORE; ROREp, proximal RORE. (b) The AGGTCA half-site in the proximal RORE was changed to AGGCCT by site-directed mutagenesis of nucleotides -518 (A to T) and -520 (T to C), and luciferase activities of each cell either untreated or treated with LPS for $24 \mathrm{~h}$ were determined. ROREpm, proximal RORE mutant. (c) The GGGATTTTCC half-site in the NF $\kappa$ BRE was changed to GGGCCCTTCC by site-directed mutagenesis of nucleotides -86 (T to C), -87 ( $\mathrm{T}$ to $\mathrm{C}$ ), and -88 (A to C), and luciferase activities of each cell either untreated or treated with LPS for $24 \mathrm{~h}$ were determined. NF $\kappa \mathrm{BREm}$, NF $\kappa$ BRE mutant. Luciferase values were normalized using Renilla luciferase. The data are presented as the means \pm S.E. from sextuplicate cultures. ${ }^{*} P<0.05$ versus vector control. 
that in RAWror cells was lower than that in RAWvecA cells in the presence of LPS (Figure 4(a)). We also investigated whether two ROREs in the il6 promoter were essential for ROR $\alpha$-mediated enhancement of il6 expression. The mutation of a proximal RORE abrogated the enhancement of the promoter activities in RAWror cells transfected with either distal or proximal construct in the absence of LPS (Figure 4(b)), suggesting that the positive regulatory effects of ROR $\alpha$ on the il 6 expression are mainly dependent on the proximal RORE in the il6 promoter. However, the mutation of the proximal RORE additionally repressed the promoter activities in RAWror transfected with the distal construct as well as the proximal construct in the presence of LPS (Figure 4(b)). Therefore, we hypothesized that ROR $\alpha$ also suppressed il6 promoter activity via the inhibition of NF $\kappa \mathrm{B}-$ induced transactivation after LPS stimulation as is the case with REV-ERB $\alpha$. In fact, the activity of an il6 promoter containing an NF $\kappa$ BRE mutated construct in RAWror cells was higher than that in RAWvecA cells in both the absence and presence of LPS (Figure 4(c)). These results show that ROR $\alpha$ activated il 6 promoter activity through proximal RORE in nonactivated cells, whereas it indirectly repressed the activity through negative regulation of $\mathrm{NF} \kappa \mathrm{B}$ signaling in activated cells. A double mutation of RORE and NF $\kappa$ BRE showed no changes in the promoter activity between RAWror and RAWvecA cells in the absence of LPS (Figure 4(c)). However, in the presence of LPS, il6 promoter activity of RAWror cells is lower than that of RAWvecA cells, suggesting that $\mathrm{ROR} \alpha$ also repressed il6 promoter activity through other transcriptional regulators than $\mathrm{NF} \kappa \mathrm{B}$.

3.8. Peritoneal Macrophages from rev-erb $\alpha$ Knockout Mice Display Increases in the il6 Gene Expression. To test whether results observed in the in vitro study are physiologically relevant, we investigated the effects of a rev-erb $\alpha$ deficiency on il6 expression in peritoneal macrophages using rev$e r b \alpha^{-1-}$ mice. As shown in Figure 5, il6 gene expression in the absence of LPS in the peritoneal macrophages of rev$e r b \alpha^{-/-}$mice was significantly higher than that in wild-type mice. The induction of the il6 gene following a LPS challenge in the peritoneal macrophage of mice lacking rev-erb $\alpha$ also was relatively higher $(P=0.08)$ than that found in wildtype mice. These results show that $i l 6$ expression is negatively regulated by REV-ERB $\alpha$ in vivo as well as in vitro.

\section{Discussion}

Until recently, REV-ERB $\alpha$ was considered to be a constitutively active nuclear orphan receptor, although heme has now been shown to bind reversibly to the receptor and to drive ligand-dependent activity [19]. This implies that REV-ERB $\alpha$ is responsive to the cellular redox state and perhaps to gaseous signaling molecules such as $\mathrm{NO}$ and $\mathrm{CO}$ through interactions with heme [20]. In addition, REV-ERB $\alpha$ acts as a transrepressor for a number of genes, including bmal1 [14], apolipoprotein AI (apoAI) [21], apoCIII [22], fibrinogen- $\beta$ [23], plasminogen activator inhibitor type 1 (pai1) [24], il6 [7], and $c c l 2$ [5], which indicates that the nuclear hormone receptor plays an important role in the regulation of metabolism, the cardiovascular system, and inflammation.

Recently, we demonstrated that REV-ERB $\alpha$ negatively regulates the inflammatory function of macrophages through the direct repression of $c c l 2$ expression [5]. Furthermore, we showed that REV-ERB $\alpha$ suppresses not only intracellular signals such as extracellular signal-regulated protein kinase (ERK) and p38 mitogen-activated protein kinase (p38 MAPK), which is known as CCL2 and the receptor chemokine (C-C motif) receptor 2- (CCR2-) activated signaling pathways, but also the inflammatory functions of macrophages such as adherent and migratory activities, the activation of which is known to be dependent on CCL2mediated ERK and p38, respectively $[5,25]$. These observations identified the nuclear hormone receptor REV-ERB $\alpha$ as an anti-inflammatory receptor and a therapeutic target in inflammatory disease.

As in the previous report, for the current study, we analyzed the role of REV-ERB $\alpha$ in the gene expression of inflammatory cytokine il 6 in murine macrophages. We confirmed that REV-ERB $\alpha$ agonist GSK4112 inhibits the induction of the il6 gene in murine peritoneal macrophages and in murine macrophage cell line RAW264 cells following LPS stimulation. Our results are consistent with the recently published results by Gibbs et al. [6] who demonstrated that GSK4112 abolishes the induction of inflammation-related genes, including il6, following a LPS challenge, using primary human monocyte-derived macrophages. In the current study, the overexpression of rev-erb $\alpha$ also revealed that REV-ERB $\alpha$ contributes to the negative regulation of il6 expression in macrophages. By contrast, peritoneal macrophages from mice lacking rev-erb $\alpha$ increase il6 gene expression. Reporter assay and site-directed mutagenesis identified a critical role for the proximal RORE in the murine il6 promoter in REV$\mathrm{ERB} \alpha$-mediated repression of il6 expression. We also showed that REV-ERB $\alpha$ represses il6 expression not only directly through a RORE but also indirectly through an $\mathrm{NF} \kappa \mathrm{BRE}$ in the murine il6 promoter. These results strongly suggest that REV-ERB $\alpha$ functions as a repressor of inflammatory response in macrophages via the inhibition of the target genes, including $c c l 2$ and $i l 6$.

REV-ERB $\alpha$ has been known to cross-talk with ROR $\alpha$, an orphan nuclear receptor encoded by $n r 1 f 1$, that has similar DNA binding specificity to REV-ERB $\alpha$, acts as a constitutive transcriptional activator, and thus competes with the binding of REV-ERB $\alpha$ [3, 4, 14-17, 26]. Furthermore, Journiac and coworkers [7] have shown that REV-ERB $\alpha$ and/or ROR $\alpha$ directly bind to a RORE in the human il6 promoter and acts as a transrepressor and a transactivator of $i l 6$ gene expression, respectively. We also confirmed that $\mathrm{ROR} \alpha$ overexpression in murine macrophage cell line enhances $i l 6$ gene expression and the promoter activity through RORE in its promoter region without any exogenous LPS stimulation, whereas it suppressed il6 gene induction and the promoter activity, at least partly, via the inhibition of $\mathrm{NF} \kappa \mathrm{B}$-induced transactivation after LPS stimulation. These results suggest that ROR $\alpha$ transactivates il6 expression by interacting with a RORE in the promoter of murine macrophages, whereas ROR $\alpha$ 


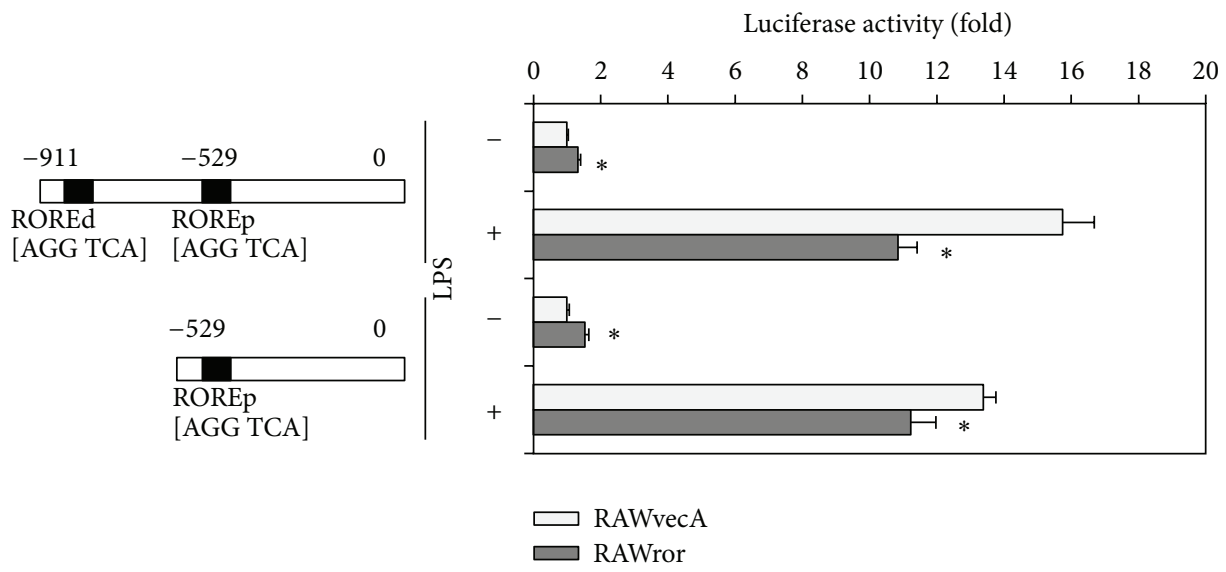

(a)

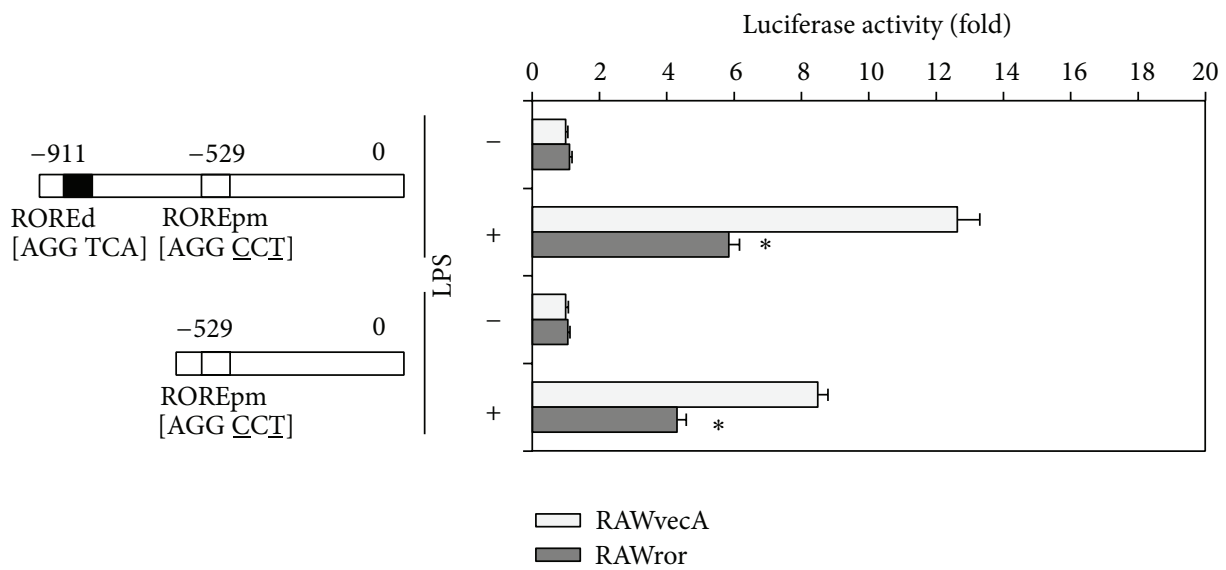

(b)

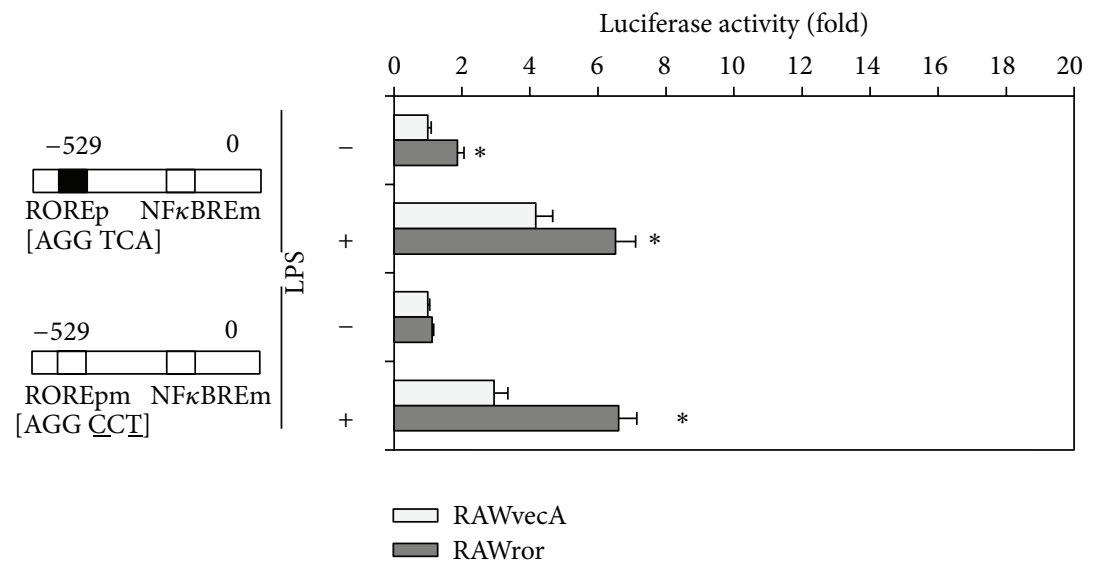

(c)

FIGURE 4: Effect of ROR $\alpha$ on il6 promoter activity. (a) RAWror and RAWvecA cells were transiently transfected with luciferase reporter construct containing either a distal or a proximal construct of $i l 6$ promoter. After treatment with or without $1 \mu \mathrm{g} / \mathrm{mL}$ LPS for $24 \mathrm{~h}$, luciferase activities were determined. ROREd, distal RORE; ROREp, proximal RORE. (b) The AGGTCA half-site in the proximal RORE was changed to AGGCCT by site-directed mutagenesis of nucleotides -518 (A to T) and -520 ( T to C), and luciferase activities of each cell either untreated or treated with LPS for $24 \mathrm{~h}$ were determined. ROREpm, proximal RORE mutant. (c) The GGGATTTTCC half-site in the NF $\kappa$ BRE was changed to GGGCCCTTCC by site-directed mutagenesis of nucleotides -86 (T to C), -87 (T to C), and -88 (A to C), and luciferase activities of each cell either untreated or treated with LPS for $24 \mathrm{~h}$ were determined. NF $\kappa$ BREm, NF $\kappa$ BRE mutant. Luciferase values were normalized using Renilla luciferase. The data are presented as the means \pm S.E. from sextuplicate cultures. ${ }^{*} P<0.05$ versus vector control. 


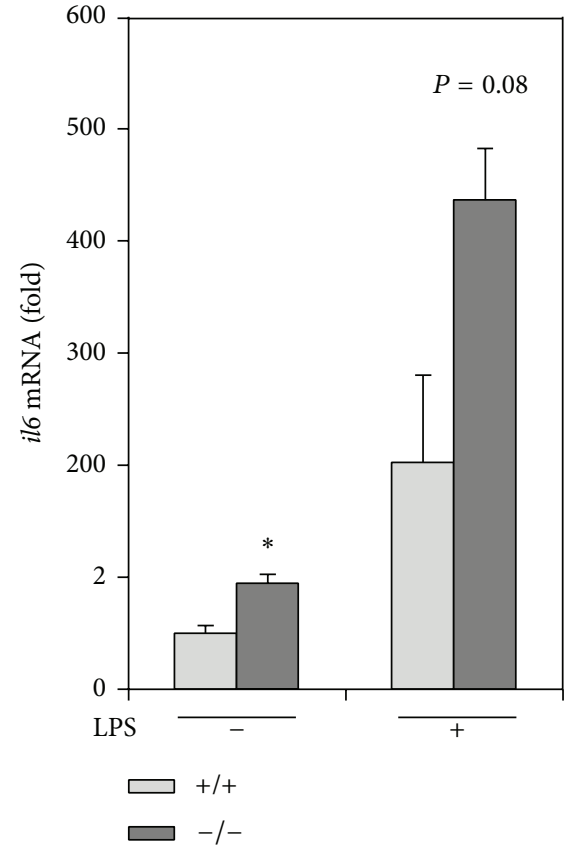

FIGURE 5: Peritoneal macrophages from $r e v-e r b \alpha^{-1-}$ mice increase il6 gene expression. Peritoneal macrophages were harvested as adherent cells from 2-month-old rev-erbo ${ }^{-/-}$mice and their wildtype $(+/+)$ mice. The cells were treated with or without $1 \mu \mathrm{g} / \mathrm{mL}$ LPS for $24 \mathrm{~h}$. The gene expression of il6 was analyzed by qPCR. For normalization, $a c t b$ mRNA was used. The data are presented as the means \pm S.E. $(n=3) .{ }^{*} P<0.05$ versus rev-erb ${ }^{+/+}$mice.

negatively regulates il6 expression through the $\mathrm{NF} \kappa \mathrm{B}$ signaling in murine macrophages. From these observations, in resting cultured macrophages, a dual regulation also pertains to the il 6 promoter activity; REV-ERB $\alpha$ potently represses il6 promoter activity, whereas ROR $\alpha$ potently enhances il6 promoter activity through murine il6 promoter as well as human [7]. The dual regulation seems to have an advantage in the modulation of inflammatory responses of macrophages, although evidence for in vivo relevance is clearly lacking.

Patients with rheumatoid arthritis (RA) report daily variations in their symptoms, experiencing greater joint pain, stiffness, and functional disability in the mornings, which is accompanied by fluctuations in circulating IL6 concentration $[27,28]$. Some asthma patients experience nighttime exacerbations that can be attributed to not only daily variations in lung physiology but also increased bronchial responsiveness at night [29]. Macrophages exhibit a rhythmic expression of rev-erb $\alpha$, are capable of cell-autonomous gene oscillation in culture, and display a robust circadian gating in their responses to exogenous inflammatory stimulation $[6,30-$ 32]. Therefore, it seems likely that REV-REB $\alpha$ expressed in macrophages plays an important role in the regulation of the diurnal fluctuation of several inflammatory diseases as well as in the production and secretion of these inflammatory and/or anti-inflammatory factors. Further studies are needed to clarify the in vivo relationship between REV-ERB $\alpha$ and inflammatory diseases. Taken together, the results of the current study indicate that REV-ERB $\alpha$ is a potent antiinflammatory receptor and a therapeutic target for inflammatory diseases.

\section{Conclusion}

We demonstrated that a circadian clock gene, REV-ERB $\alpha$, represses il6 expression not only indirectly through an $\mathrm{NF} \kappa \mathrm{B}$ binding motif but also directly through a REV-ERB $\alpha$ binding motif in the murine il6 promoter region. Overexpression of rev-erb $\alpha$ in murine macrophage cell line suppressed il6 induction and $\mathrm{NF} \kappa \mathrm{B}$ activity following a LPS endotoxin challenge. The present study also showed that peritoneal macrophages from mice lacking rev-erb $\alpha$ display increases in il6 expression. These data suggest that REV-ERB $\alpha$ regulates the inflammatory response of macrophages through the suppression of il 6 expression. REV-ERB $\alpha$ may therefore be a key link between clockwork and inflammation.

\section{Abbreviations \\ NF $\kappa$ BRE: Nuclear factor $\kappa \mathrm{B}$ response element ROR: Retinoic acid receptor-related orphan receptor RORE: ROR response element.}

\section{Conflict of Interests}

The authors declare that there is no conflict of interests regarding the publication of this paper.

\section{Acknowledgments}

This work was supported, in whole or in part, by the Japanese Ministry of Education, Culture Sports, Science and Technology (to Takako Kizaki and Hideki Ohno) and the Nakatomi foundation (to Shogo Sato).

\section{References}

[1] D. A. Bechtold, J. E. Gibbs, and A. S. I. Loudon, "Circadian dysfunction in disease," Trends in Pharmacological Sciences, vol. 31, no. 5, pp. 191-198, 2010.

[2] N. Preitner, F. Damiola, L. Lopez-Molina et al., "The orphan nuclear receptor REV-ERB $\alpha$ controls circadian transcription within the positive limb of the mammalian circadian oscillator," Cell, vol. 110, no. 2, pp. 251-260, 2002.

[3] H. P. Harding and M. A. Lazar, "The orphan receptor Rev$\operatorname{ErbA} \alpha$ activates transcription via a novel response element," Molecular and Cellular Biology, vol. 13, no. 5, pp. 3113-3121, 1993.

[4] H. P. Harding and M. A. Lazar, "The monomer-binding orphan receptor Rev-Erb represses transcription as a dimer on a novel direct repeat," Molecular and Cellular Biology, vol. 15, no. 9, pp. 4791-4802, 1995.

[5] S. Sato, T. Sakurai, J. Ogasawara et al., "A circadian clock gene, Rev-erb $\alpha$, modulates the inflammatory function of macrophages through the negative regulation of $\mathrm{Ccl} 2$ expression," Journal of Immunology, vol. 192, no. 1, pp. 407-417, 2014.

[6] J. E. Gibbs, J. Blaikley, S. Beesley et al., "The nuclear receptor REV-ERB $\alpha$ mediates circadian regulation of innate immunity 
through selective regulation of inflammatory cytokines," Proceedings of the National Academy of Sciences of the United States of America, vol. 109, no. 2, pp. 582-587, 2012.

[7] N. Journiac, S. Jolly, C. Jarvis et al., "The nuclear receptor ROR $\alpha$ exerts a bi-directional regulation of IL-6 in resting and reactive astrocytes," Proceedings of the National Academy of Sciences of the United States of America, vol. 106, no. 50, pp. 21365-21370, 2009.

[8] S. Copeland, H. S. Warren, S. F. Lowry, S. E. Calvano, and D. Remick, "Acute inflammatory response to endotoxin in mice and humans," Clinical and Diagnostic Laboratory Immunology, vol. 12, no. 1, pp. 60-67, 2005.

[9] T. Kizaki, T. Maegawa, T. Sakurai et al., "Voluntary exercise attenuates obesity-associated inflammation through ghrelin expressed in macrophages," Biochemical and Biophysical Research Communications, vol. 413, no. 3, pp. 454-459, 2011.

[10] K. Shirato, T. Kizaki, T. Sakurai et al., "Hypoxia-inducible factor- $1 \alpha$ suppresses the expression of macrophage scavenger receptor 1," Pflugers Archiv European Journal of Physiology, vol. 459, no. 1, pp. 93-103, 2009.

[11] T. Kizaki, S. Oh-Ishi, T. Ookawara, M. Yamamoto, T. Izawa, and H. Ohno, "Glucocorticoid-mediated generation of suppressor macrophages with high density Fc $\gamma$ RII during acute cold stress," Endocrinology, vol. 137, no. 10, pp. 4260-4267, 1996.

[12] T. Kizaki, K. Suzuki, Y. Hitomi et al., "Uncoupling protein 2 plays an important role in nitric oxide production of lipopolysaccharide-stimulated macrophages," Proceedings of the National Academy of Sciences of the United States of America, vol. 99, no. 14, pp. 9392-9397, 2002.

[13] T. Kizaki, T. Ookawara, K. Iwabuchi et al., "Age-associated increase of basal corticosterone levels decreases ED2 $2^{\text {high }}$, NF$\kappa \mathrm{B}^{\text {high }}$ activated macrophages," Journal of Leukocyte Biology, vol. 68, no. 1, pp. 21-30, 2000.

[14] H. R. Ueda, W. Chen, A. Adachi et al., "A transcription factor response element for gene expression during circadian night," Nature, vol. 418, no. 6897, pp. 534-539, 2002.

[15] F. Guillaumond, H. Dardente, V. Giguère, and N. Cermakian, "Differential control of Bmall circadian transcription by REVERB and ROR nuclear receptors," Journal of Biological Rhythms, vol. 20, no. 5, pp. 391-403, 2005.

[16] H. P. Harding, G. B. Atkins, A. B. Jaffe, W. J. Seo, and M. A. Lazar, "Transcriptional activation and repression by ROR $\alpha$, an orphan nuclear receptor required for cerebellar development," Molecular Endocrinology, vol. 11, no. 11, pp. 1737-1746, 1997.

[17] B. M. Forman, J. Chen, B. Blumberg et al., "Cross-talk among ROR $\alpha 1$ and the Rev-erb family of orphan nuclear receptors," Molecular Endocrinology, vol. 8, no. 9, pp. 1253-1261, 1994.

[18] M. J. May and S. Ghosh, "Signal transduction through NF- $\kappa$ B," Immunology Today, vol. 19, no. 2, pp. 80-88, 1998.

[19] S. Raghuram, K. R. Stayrook, P. Huang et al., "Identification of heme as the ligand for the orphan nuclear receptors REV-ERB $\alpha$ and REV-ERB $\beta$," Nature Structural and Molecular Biology, vol. 14, no. 12, pp. 1207-1213, 2007.

[20] M. Teboul, A. Gréchez-Cassiau, F. Guillaumond, and F. Delaunay, "How nuclear receptors tell time," Journal of Applied Physiology, vol. 107, no. 6, pp. 1965-1971, 2009.

[21] N. Vu-Dac, S. Chopin-Delannoy, P. Gervois et al., “The nuclear receptors peroxisome proliferator-activated receptor $\alpha$ and rev$\operatorname{erb} \alpha$ mediate the species-specific regulation of apolipoprotein A-I expression by fibrates," Journal of Biological Chemistry, vol. 273, no. 40 , pp. 25713-25720, 1998.
[22] E. Raspé, H. Duez, A. Mansén et al., "Identification of Rev-erb $\alpha$ as a physiological repressor of apoC-III gene transcription," Journal of Lipid Research, vol. 43, no. 12, pp. 2172-2179, 2002.

[23] C. Chauvet, B. Bois-Joyeux, C. Fontaine et al., "The gene encoding fibrinogen- $\beta$ is a target for retinoic acid receptorrelated orphan receptor $\alpha$, Molecular Endocrinology, vol. 19, no. 10, pp. 2517-2526, 2005.

[24] J. Wang, L. Yin, and M. A. Lazar, “The orphan nuclear receptor Rev-erb $\alpha$ regulates circadian expression of plasminogen activator inhibitor type 1," Journal of Biological Chemistry, vol. 281, no. 45, pp. 33842-33848, 2006.

[25] N. Ashida, H. Arai, M. Yamasaki, and T. Kita, "Distinct signaling pathways for MCP-1-dependent integrin activation and chemotaxis," The Journal of Biological Chemistry, vol. 276, no. 19, pp. 16555-16560, 2001.

[26] H. Migita, J. Morser, and K. Kawai, "Rev-erb $\alpha$ upregulates NF$\rho$ B-responsive genes in vascular smooth muscle cells," The FEBS Letters, vol. 561, no. 1-3, pp. 69-74, 2004.

[27] R. H. Straub and M. Cutolo, "Circadian rhythms in rheumatoid arthritis: implications for pathophysiology and therapeutic management," Arthritis \& Rheumatism, vol. 56, no. 2, pp. 399408, 2007.

[28] M. G. Perry, J. R. Kirwan, D. S. Jessop, and L. P. Hunt, "Overnight variations in cortisol, interleukin 6, tumor necrosis factor $\alpha$ and other cytokines in people with rheumatoid arthritis," Annals of the Rheumatic Diseases, vol. 68, no. 1, pp. 63-68, 2009.

[29] E. Ferraz, M. C. Borges, J. Terra-Filho, J. A. B. Martinez, and E. O. Vianna, "Comparison of 4 AM and 4 PM bronchial responsiveness to hypertonic saline in asthma," Lung, vol. 184, no. 6, pp. 341-346, 2006.

[30] M. Hayashi, S. Shimba, and M. Tezuka, "Characterization of the molecular clock in mouse peritoneal macrophages," Biological \& Pharmaceutical Bulletin, vol. 30, no. 4, pp. 621-626, 2007.

[31] M. Keller, J. Mazuch, U. Abraham et al., "A circadian clock in macrophages controls inflammatory immune responses," Proceedings of the National Academy of Sciences of the United States of America, vol. 106, no. 50, pp. 21407-21412, 2009.

[32] A. C. Silver, A. Arjona, W. E. Walker, and E. Fikrig, "he circadian clock controls toll-like recept or 9-mediated innate and adaptive immunity," Immunity, vol. 36, no. 2, pp. 251-261, 2012. 


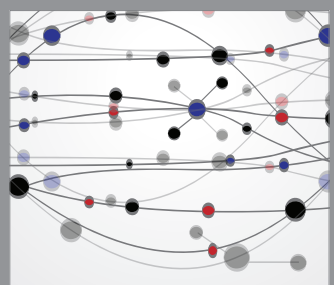

The Scientific World Journal
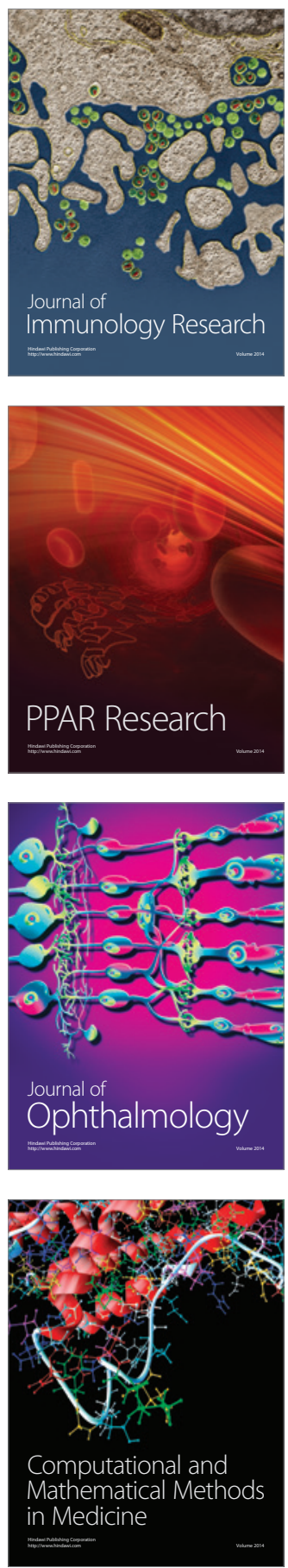

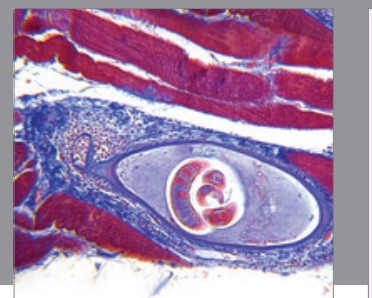

Gastroenterology

Research and Practice
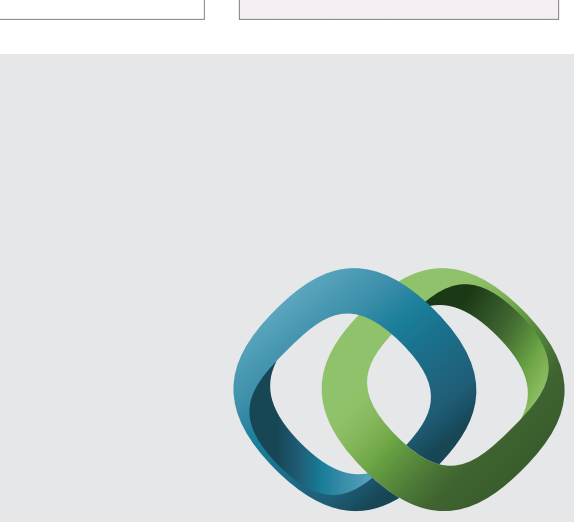

\section{Hindawi}

Submit your manuscripts at

http://www.hindawi.com
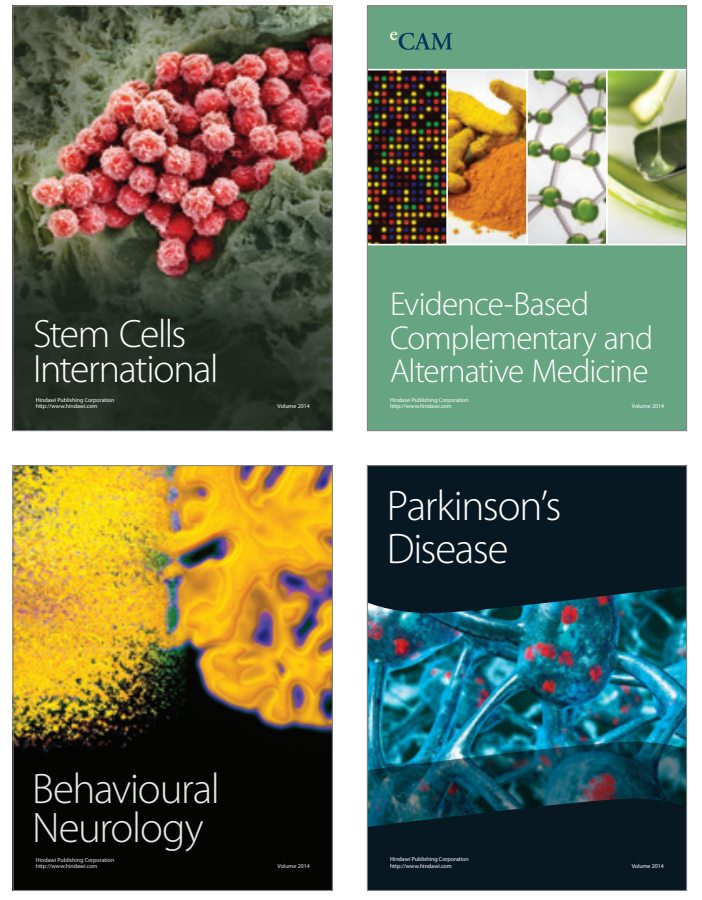
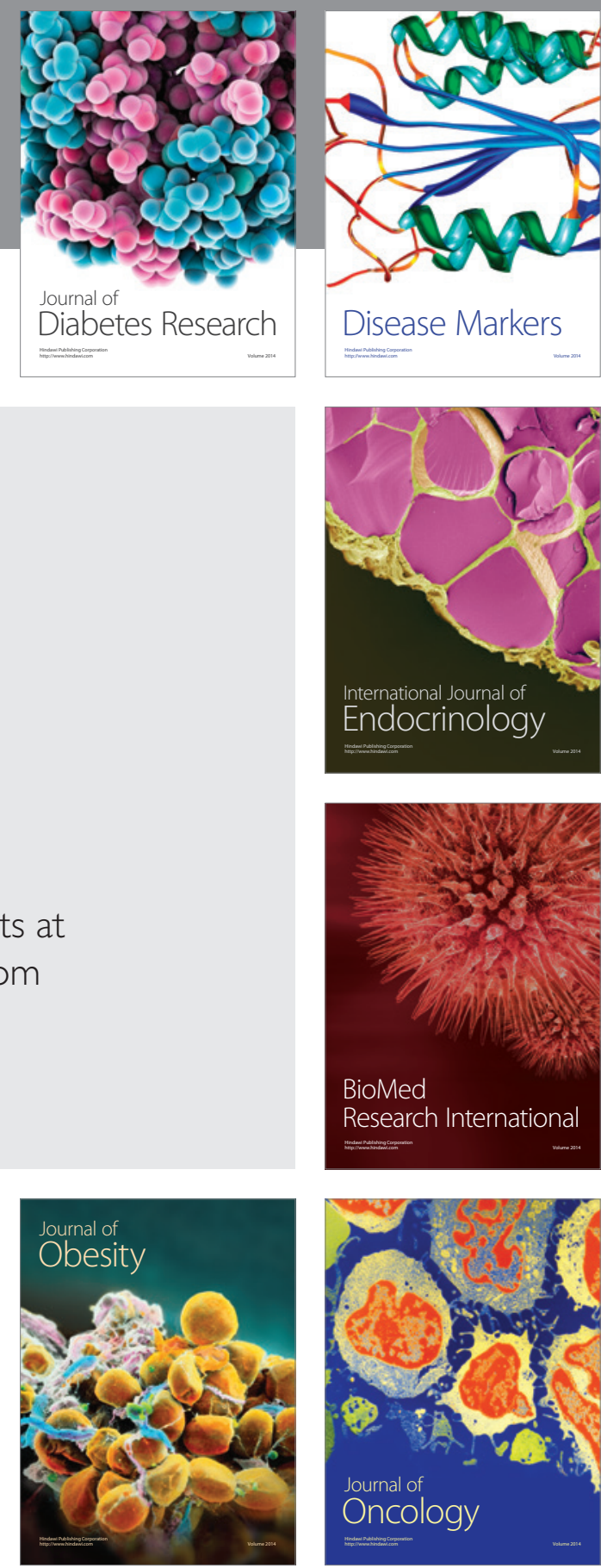

Disease Markers
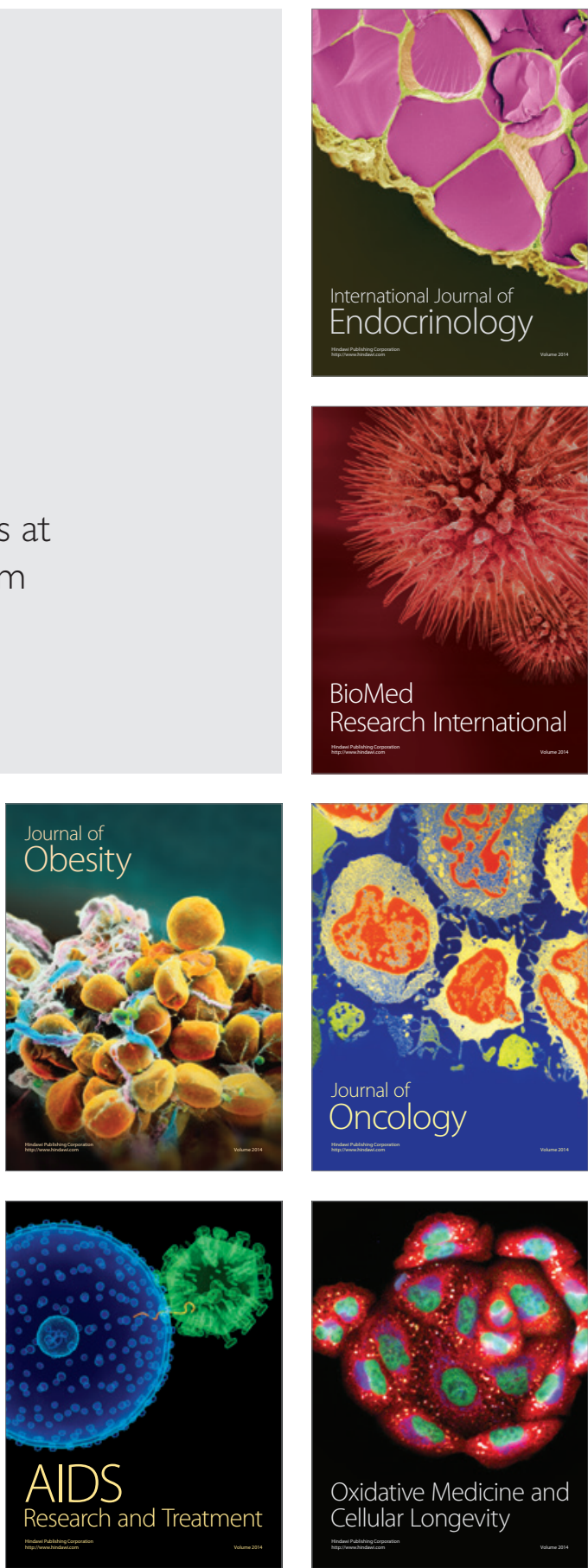